\title{
A Combined Multipulse-Multilevel Inverter Suitable For High Power Applications
}

\author{
B. Geethalakshmi and P. Dananjayan
}

\begin{abstract}
Power electronic devices are finding increased applications in the transformation of electrical energy into useful forms, especially at higher power levels. The recent trend in power electronic converters is to switch the power semiconductor devices in power modulators at increased frequencies with a view to minimize harmonics, enhance power quality and regulate the output voltage. This paper is aimed to present the design of high power inverter topology capable of producing a near sinusoidal ac voltage with minimal harmonic distortion which enables its use in high power applications. The analytical expressions for the proposed inverter output voltages using Fourier analysis have been obtained. Vector diagrams are drawn to clearly illustrate the mechanism of harmonic cancellation in the proposed multipulse-multilevel inverter topology. The complete digital simulation of the proposed VSI is performed using MATLAB/Simulink and the simulation results closely agreed with the analytical results.
\end{abstract}

Index Terms - Multi-pulse inverter, Multi-level inverter, Phase shifting transformer, Total Harmonic Distortion, Voltage source inverter.

\section{INTRODUCTION}

The progress of a nation is assessed by its economic growth, industrial development besides technological advancements. The per capita consumption of electrical energy is treated as a measure to evaluate the overall progress. It is imperative that the existing resources are fully utilized before venturing to look for alternatives, in the present energy crisis scenario. However, it is equally important to realize the rapid depletion of energy sources and contemplate measures to augment its sustainability.

The field of power electronics has witnessed tremendous development in recent times. The advent of new power controlled devices has contributed significantly to an enhanced performance of the existing power converters. The birth of innovative converter topologies has paved the way for further improving the overall power quality. It has contributed to build sophisticated utilities and enable precise control of flow of power over the transmission lines.

Manuscript received May 14, 2009.

B.Geethalakshmi is with the Department of Electrical and Electronics Engineering, Pondicherry Engineering College, Pondicherry, India (e-mail: bgeethalakshmi_pec@yahoo.co.in).

P.Dananjayan is with the Department of Electronics and Communication Engineering, Pondicherry Engineering College, Pondicherry, India. (Corresponding Author - Phone:9443768716; fax:04132655101; email-pdananjayan@rediffmail.com).
Inverters are generally used in a host of applications that include variable speed drive, uninterruptible power supplies, flexible AC transmission systems (FACTS), high voltage dc transmission (HVDC) systems, active filters, etc., The output voltage waveforms of ideal inverters should be sinusoidal. But, the waveforms of practical inverters are non-sinusoidal and contain certain harmonics. Square wave or quasi-square wave voltages may be acceptable for low- and medium-power applications. However, low distorted sinusoidal waveforms are required for high power applications especially when they are used in power system applications.

Appropriate voltage source inverter circuits have to be developed in order to integrate power converter circuits into power systems. The harmonics generated on the ac side of the power inverter circuits greatly influence the power quality of the transmission system. Hence, in the present work, an attempt is made to propose a suitable inverter configuration useful for high power applications.

\section{EVOLUTION OF HIGH POWER INVERTERS}

The traditional two-level VSI produces a square wave output as it switches the direct voltage source on and off. However for high voltage applications, a near sinusoidal ac voltage with minimal harmonic distortion is required. In order to realise higher voltages, each main switch of the 2-level inverter is formed by connecting many semiconductor devices in a series/parallel fashion. It is essential that with this arrangement, the electrical and thermal characteristics of the series and/or parallel connected semiconductor devices should be matched [1].

In response to the growing demand for high power inverter units, multipulse inverters (MPI) have drawn increased interest in the field of research and industry [2-4]. A multipulse inverter generates a staircase wave closely resembling a sine wave by connecting number of identical three-phase inverter bridges through phase shifting transformers (PST). The high power STATCOM commissioned at Sullivan substation, United States used 48-pulse voltage source inverter in order to obtain higher operating voltages with less harmonic content [6]. The key problem with the multipulse inverter is the requirement of magnetic interfaces constituted by complex zig-zag phase shifting transformers which tremendously increases the cost of the complete system [1].

An attractive alternative to the multipulse inverter is the multilevel inverter (MLI) [6-11] which has evolved in three different topologies namely diode clamped multilevel inverter 
(DCMLI), [6, 7] flying capacitor multilevel inverter (FCMLI) [8] and cascaded multilevel inverter (CMLI) [9, 10]. Among the three configurations, the CMLI with a separate dc capacitor is widely accepted for applications in high power drives and utility systems due to its modularized circuit layout and sufficiently high operating voltages [11].

Though the basic concept of the CMLI has existed over more than two decades, it was not fully realized until F.Z.Peng and J.S.Lai [9] patented it. The CMLI consists of a number of $\mathrm{H}$-bridge power conversion cells with each cell supplied by an isolated source on the dc side and series connected on the ac side so as to produce a staircase waveform. A premium quality output waveform can be achieved with a sufficiently high number of voltage levels. However, the number of voltage levels is limited due to control complexity and cost. Besides, a large number of dc capacitors are required whose voltages must be balanced in order to avoid over-voltages on any particular link. The critical review of literature shows neither multipulse inverter nor multilevel inverter is useful on their own. A hybrid inverter topology incorporating the advantages of both MPI and MLI will be attractive.

In the present work it is proposed to build up a forty eight pulse inverter topology through the twenty four pulse configuration in which each individual two level inverters are converted to 3-level diode clamped structures. This new topology enjoys the benefits of both the MPI and MLI configurations and is referred as combined multipulse-multilevel inverter topology. The harmonic performance of this inverter topology is evaluated through MATLAB based simulation. It establishes that this structure almost offers the same response as that of a forty eight pulse inverter in respect of THD.

\section{Proposed INVERTER TOPOLOGY}

The proposed configuration shown in Fig. 1 is obtained by combining four three-level diode clamped multilevel inverters with an adequate phase shifts between them. The voltages generated by each of the three level inverters are applied to the secondary windings of four different PSTs. Two of them are Y-Y transformers with a turns ratio of $1: 1$ and the remaining two are $\Delta-Y$ transformers with a turns ratio of $1: \sqrt{3}$. The primary windings of the PSTs are connected in series and the proper pulse pattern as tabulated in Table I is maintained so that the fundamental components of the individual 3-level inverters are added in phase on the primary side.

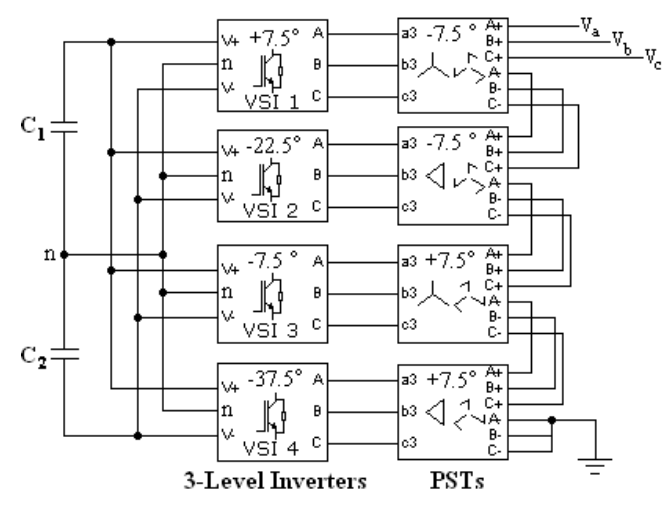

Fig. 1 Combined multipulse-multilevel inverter

In this configuration the number of PST requirement is reduced to half of that needed in 48-pusle operation. Though the configuration is similar to a 24-pulse inverter, it provides very less THD as that of the 48-pulse inverter. This is possible by selectively eliminating the $23^{\text {rd }}$ and $25^{\text {th }}$ harmonic components through the appropriate selection of the conduction angle $(\sigma)$ of the individual three-level inverter units.

TABLE I PHASE DISPLACEMENT FOR THE COMBINED

MULTIPULSE-MULTILEVEL INVERTER

\begin{tabular}{|c|c|c|}
\hline $\begin{array}{c}\text { Coupling } \\
\text { transformer }\end{array}$ & $\begin{array}{c}\text { Gate pulse } \\
\text { pattern }\end{array}$ & $\begin{array}{c}\text { Phase shifting } \\
\text { transformer }\end{array}$ \\
\hline$Y-Y$ & $+7.5^{\circ}$ & $-7.5^{\circ}$ \\
\hline$\Delta-Y$ & $-22.5^{\circ}$ & $-7.5^{\circ}$ \\
\hline$Y-Y$ & $-7.5^{\circ}$ & $+7.5^{\circ}$ \\
\hline$\Delta-Y$ & $-37.5^{\circ}$ & $+7.5^{\circ}$ \\
\hline
\end{tabular}

Each unit in the proposed structure is a diode clamped three-level inverter configuration as shown in Fig.2. The dc-bus voltage is split into three levels by two series connected bulk capacitors, $\mathrm{C}_{1}$ and $\mathrm{C}_{2}$. The output voltage $\mathrm{v}_{\text {an }}$ has three states namely $\mathrm{V}_{\mathrm{dc}} / 2,0$ and $-\mathrm{V}_{\mathrm{dc}} / 2$ when the switch pairs $\mathrm{S}_{1}$ \& $\mathrm{S}_{2}, \mathrm{~S}_{2} \& \mathrm{~S}_{1}{ }^{\prime}$ and $\mathrm{S}^{\prime}{ }^{\prime} \& \mathrm{~S}_{2}{ }^{\prime}$ are switched $\mathrm{ON}$ respectively. In general the conduction angle $\sigma$ of the three- level inverter is chosen as

$$
\sigma=180^{\circ}\left(1-\frac{1}{\mathrm{~m}}\right)
$$

where $\mathrm{m}$ is the harmonic component which is to be eliminated. 


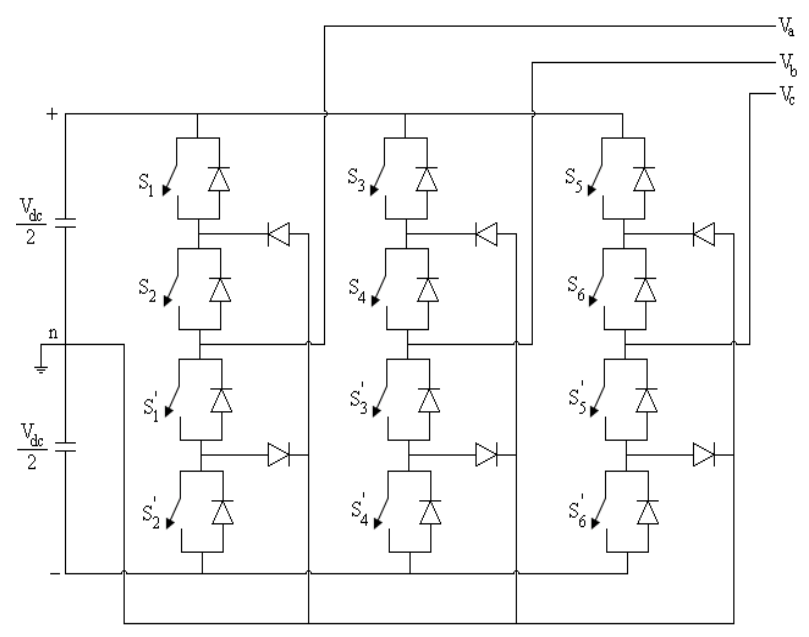

Fig.2 Diode clamped 3-level inverter

\section{HARMONIC ANALYSIS}

The phase-to-phase voltage and the phase-to-neutral voltage of a single three level diode clamped multilevel inverter with conduction angle $\sigma$ are described in Fig.3.

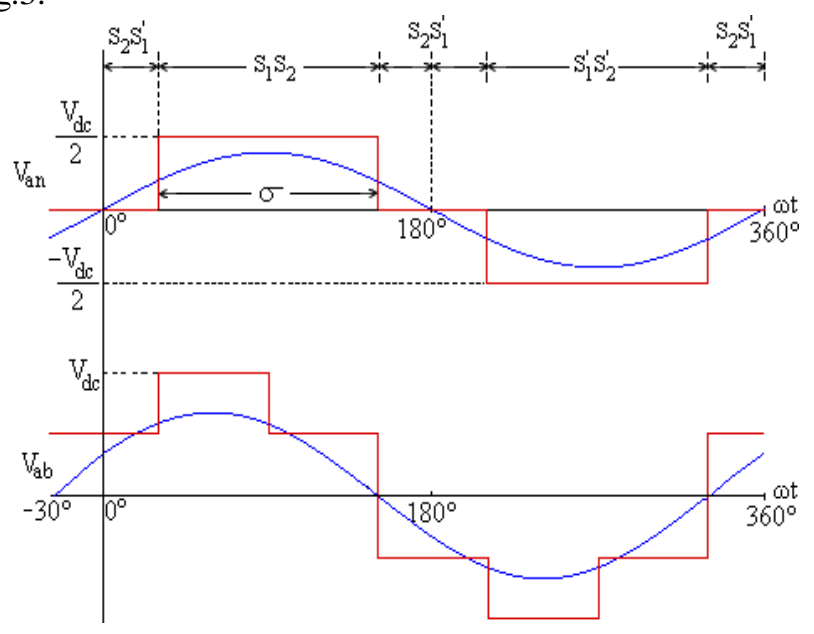

Fig.3 Phase and line voltages of 3-level inverter

Carrying out the Fourier analysis of the inverter output voltage, the instantaneous phase-to-neutral voltage is expressed as:

$\mathrm{v}_{\mathrm{an}}(\mathrm{t})=\sum_{\mathrm{m}=1}^{\infty} \mathrm{V}_{\mathrm{an}} \sin \mathrm{m} \omega \mathrm{t}$

where $\mathrm{V}_{\mathrm{an}_{\mathrm{m}}}=\frac{4}{\pi} \int_{\frac{\pi-\sigma}{2}}^{\frac{\pi}{2}} \frac{\mathrm{V}_{\mathrm{DC}}}{2} \sin m \omega \mathrm{t} \mathrm{d}(\omega \mathrm{t})$

(3)

$$
\mathrm{V}_{\mathrm{an}_{\mathrm{m}}}=\frac{2 \mathrm{~V}_{\mathrm{DC}}}{\mathrm{m} \pi} \cos \mathrm{m}\left(\frac{\pi-\sigma}{2}\right)
$$

Similarly the instantaneous phase-to-phase voltage is expressed as

$\mathrm{v}_{\mathrm{ab}}(\mathrm{t})=\sum_{\mathrm{m}=1}^{\infty} \mathrm{V}_{\mathrm{ab}} \sin \left(\mathrm{m} \omega \mathrm{t}+\mathrm{m} \frac{\pi}{6}\right)$

(5) where

$\mathrm{V}_{\mathrm{ab}_{\mathrm{m}}}=\frac{4}{\pi}\left[\int_{-\frac{\pi-\sigma}{2}}^{\frac{\pi-\sigma}{2}} \frac{\mathrm{V}_{\mathrm{DC}}}{2} \operatorname{sinm}\left(\omega \mathrm{t}+\frac{\pi}{6}\right) d(\omega \mathrm{t})+\int_{\frac{\pi-\sigma}{2}}^{\frac{\pi}{3}} \mathrm{~V}_{\mathrm{DC}} \sin \mathrm{m}\left(\omega \mathrm{t}+\frac{\pi}{6}\right) d(\omega \mathrm{t})\right]$

$\mathrm{V}_{\mathrm{ab}}=\frac{4 \mathrm{~V}_{\mathrm{DC}}}{\mathrm{m} \pi} \sin \frac{\mathrm{m} \sigma}{2} \cos \frac{\mathrm{m} \pi}{6}$

The voltages $v_{b c}(t)$ and $v_{c a}(t)$ exhibit a similar pattern except that they are phase shifted by $120^{\circ}$ and $240^{\circ}$ respectively. Similarly the phase voltages $\mathrm{v}_{\mathrm{bn}}(\mathrm{t})$ and $\mathrm{v}_{\mathrm{cn}}(\mathrm{t})$ are also phase shifted by $120^{\circ}$ and $240^{\circ}$ respectively. It contains only odd harmonics in the order of $6 r \pm 1$, where $r$ is a numeral can assume values $1,2,3, \ldots$.

In general star and delta connected windings have a relative phase shift of $30^{\circ}$ and the three-level inverters connected to each of these $\mathrm{Y}$ and $\Delta$ transformers will give an overall 12-pulse operation and offers a better harmonic performance. The output voltage will have a twelve pulse waveform, with harmonics of the order of $12 \mathrm{r} \pm 1$. Thus the twelve pulse inverter will have $11^{\text {th }}, 13^{\text {th }}, 23^{\text {rd }}, 25^{\text {th }}, \ldots$. harmonics with amplitudes of $1 / 11^{\text {th }}, 1 / 13^{\text {th }}, 1 / 23^{\text {rd }}, 1 / 25^{\text {th }}, \ldots \ldots$ respectively of the fundamental ac voltage.

The relationship between the phase-to-phase voltage and the phase-to-neutral voltage is expressed as:

$$
\mathrm{v}_{\mathrm{ab}_{\mathrm{m}}}=(-1)^{\mathrm{r}} \sqrt{3} \mathrm{v}_{\mathrm{an}_{\mathrm{m}}}
$$

For obtaining 12-pulse inverter the $\mathrm{VSI}_{1}$ output is connected to a Y-Y transformer with a 1:1 turn ratio, and the line to neutral voltage using equation (8) can be expressed as:

$$
\begin{aligned}
& \mathrm{v}_{\text {an }}(\mathrm{t})_{1}=\frac{1}{\sqrt{3}} \sum_{\mathrm{m}=1}^{\infty} \frac{\mathrm{V}_{\mathrm{ab}_{\mathrm{m}}}}{(-1)^{\mathrm{r}}} \sin \mathrm{m} \omega \mathrm{t} \\
& \forall \mathrm{m}=6 \mathrm{r} ?, \mathrm{r}=0,1,2, \ldots . .
\end{aligned}
$$

If the $\mathrm{VSI}_{2}$ produces phase-to-phase voltages lagging by $30^{\circ}$ with respect to $\mathrm{VSI}_{1}$ and with the same magnitude, it is given by

$$
\mathrm{v}_{\mathrm{ab}}(\mathrm{t})_{2}=\sum_{\mathrm{m}=1}^{\infty} \mathrm{V}_{\mathrm{ab}} \sin \mathrm{m} \omega \mathrm{t}
$$

If this inverter output is connected to a $\Delta$-Y transformer with a $1: 1 / \sqrt{ } 3$ turn ratio, the line-to-neutral voltage in the Y-connected secondary will be

$$
\mathrm{v}_{\mathrm{anY}}(\mathrm{t})_{2}=\sum_{\mathrm{m}=1}^{\infty} \mathrm{V}_{\mathrm{an}_{\mathrm{m}}} \sin \mathrm{m} \omega \mathrm{t}
$$

Therefore line-to-line voltage in the secondary side is

$$
\mathrm{v}_{\mathrm{abY}}(\mathrm{t})_{2}=\sum_{\mathrm{m}=1}^{\infty} \sqrt{3} \mathrm{~V}_{\mathrm{an}_{\mathrm{m}}} \sin \left(\mathrm{m} \omega \mathrm{t}+\frac{\mathrm{m} \pi}{6}\right)
$$

The 12-pulse inverter output is obtained by adding the equations (5) and (12).

$$
\begin{aligned}
& \mathrm{v}_{\mathrm{ab}}(\mathrm{t})_{12}=\mathrm{v}_{\mathrm{ab}}(\mathrm{t})+\mathrm{v}_{\mathrm{abY}}(\mathrm{t})_{2} \\
& \mathrm{v}_{\mathrm{ab}}(\mathrm{t})_{12}=\sum_{\mathrm{m}=1}^{\infty} \mathrm{V}_{\mathrm{ab}_{12 \mathrm{~m}}} \sin \left(\mathrm{m} \omega \mathrm{t}+\frac{\mathrm{m} \pi}{6}\right) \\
& \forall \mathrm{m}=12 \mathrm{r} ?, \mathrm{r}=0,1,2, \ldots \ldots .
\end{aligned}
$$


since $\quad \mathrm{V}_{\mathrm{ab}_{12 \mathrm{~m}}}=\mathrm{V}_{\mathrm{ab}_{\mathrm{m}}}+\sqrt{3} \mathrm{~V}_{\mathrm{an}_{\mathrm{m}}}=2 \mathrm{~V}_{\mathrm{ab}_{\mathrm{m}}}$

$$
\therefore \mathrm{v}_{\mathrm{ab}}(\mathrm{t})_{12}=2 \sum_{\mathrm{m}=1}^{\infty} \mathrm{v}_{\mathrm{ab}_{\mathrm{m}}} \sin \left(\mathrm{m} \omega \mathrm{t}+\frac{\mathrm{m} \pi}{6}\right)
$$

Similarly two twelve pulse inverters phase shifted by $15^{\circ}$ from each other can provide a 24-pulse inverter, with much lower harmonics in the ac side. The ac output voltage will have $24 \mathrm{r} \pm 1$ order harmonics, i.e., $23^{\text {rd }}, 25^{\text {th }}, 47^{\text {th }}, 49^{\text {th }}, \ldots .$. harmonics, with magnitudes of $1 / 23^{\text {rd }}, 1 / 25^{\text {th }}, 1 / 47^{\text {th }}, 1 / 49^{\text {th }}, \ldots$. respectively, of the fundamental ac voltage. Thus the output voltage of twenty four pulse inverter is obtained as:

$$
\begin{aligned}
& \mathrm{v}_{\mathrm{ab}_{24}}(\mathrm{t})=4 \sum_{\mathrm{m}=1}^{\infty} \mathrm{V}_{\mathrm{ab}_{\mathrm{m}}} \sin \left(\mathrm{m} \omega \mathrm{t}+22.5^{\text {鞍 }} \mathrm{m}+7.5 \mathrm{x}\right) \\
& \mathrm{v}_{\mathrm{an}_{24}}(\mathrm{t})=\frac{4}{\sqrt{3}} \sum_{\mathrm{m}=1}^{\infty} \mathrm{V}_{\mathrm{ab}_{\mathrm{m}}} \sin \left(\mathrm{m} \omega \mathrm{t}+22.5^{\text {荌 }} \mathrm{m}-22.5 \mathrm{x}\right)
\end{aligned}
$$

where $\mathrm{x}=1$ for positive sequence harmonics

$$
\mathrm{x}=-1 \text { for negative sequence harmonics }
$$$$
\forall \mathrm{m}=24 \mathrm{r} \text { ? }, \mathrm{r}=0,1,2, \ldots \ldots
$$

In order to eliminate the $23^{\text {rd }}$ and $25^{\text {th }}$ harmonic components, the conduction angle of the inverter is set to $\sigma=172.5^{\circ}$ by choosing $\mathrm{m}=24$ in equation (1). This configuration produces almost a near sinusoidal output voltage since the lowest significant harmonic component is the $47^{\text {th }}$ harmonic.

\section{HARMONIC NEUTRALIZATION}

The magnitude and phase angle of the harmonic components present at the outputs of the diode clamped multilevel inverters $\mathrm{VSI}_{1}$ to $\mathrm{VSI}_{4}$ are given in Figs.4-7 respectively. Since the harmonic components 5, 7, 17, $19,29,31,41,43 \ldots$ present in adjacent inverters $\left(\mathrm{VSI}_{1}\right.$ and $\mathrm{VSI}_{2}, \mathrm{VSI}_{3}$ and $\mathrm{VSI}_{4}$ ) are out of phase and have the same magnitude, they cancel each other. Similarly the harmonic components $11,13,35,37 \ldots$ present in the adjacent pairs of inverters are also cancelled. The harmonic components 23,25 , $47,49 \ldots$ which are in phase in all the four inverters add up with each other. This results to a 24-pulse inverter with the harmonic components in the order of $24 \mathrm{r} \pm 1$. Fig. 8 displays the harmonic components of the 24-pulse inverters.
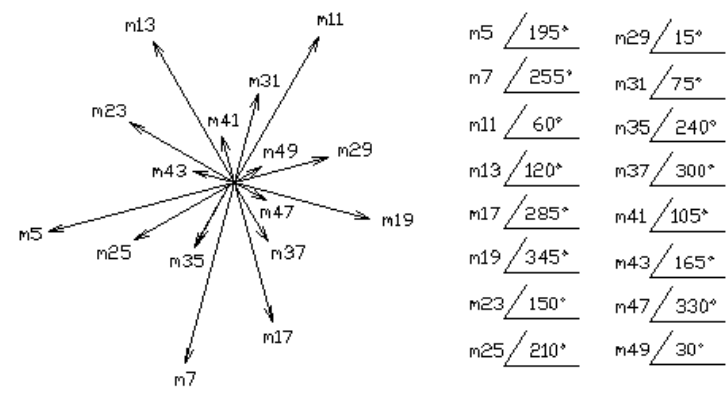

Fig 4 Three level $\mathrm{VSI}_{1}$ harmonics
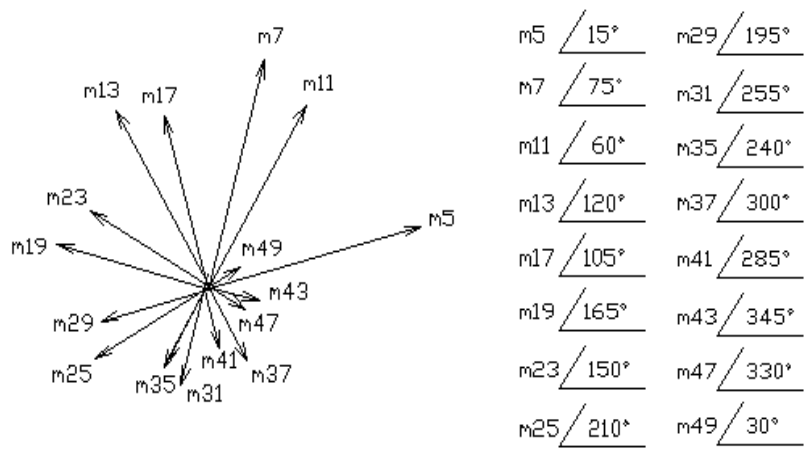

Fig 5 Three level $\mathrm{VSI}_{2}$ harmonics
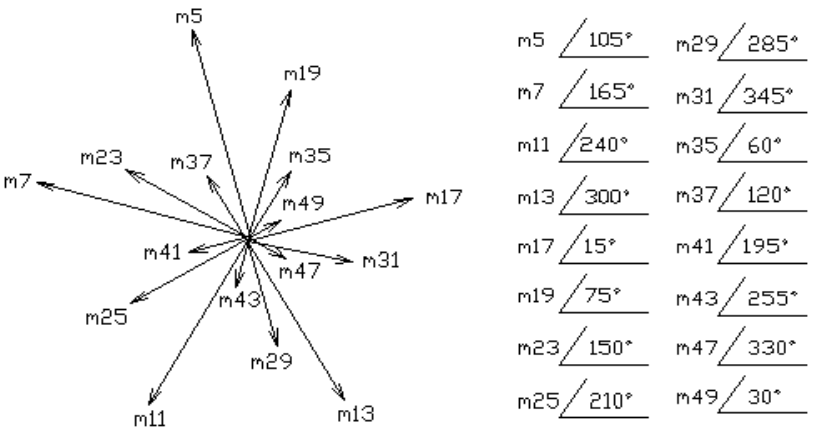

Fig 6 Three level $\mathrm{VSI}_{3}$ harmonics
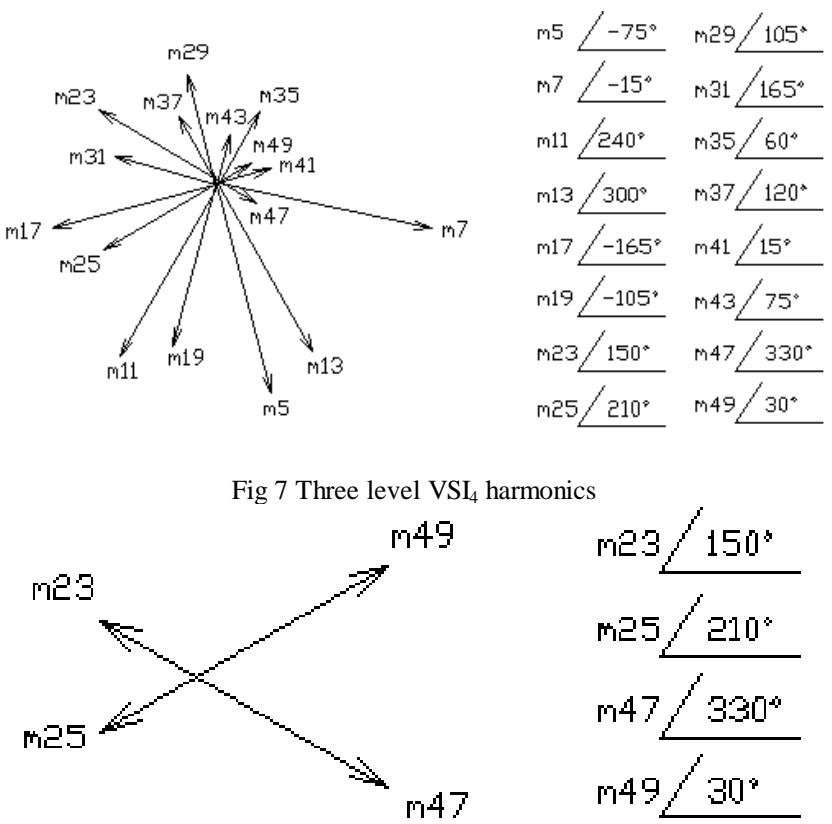

Fig 8 24-pulse inverter harmonics

\section{Simulation Results And Discussion}

The 24-pulse inverter obtained by combining MPI and MLI is simulated using MATLAB/Simulink to analyze the harmonics in its output voltage. A dc source of 2000 volts is used at the input side. The load is a star connected RL load of $10 \mathrm{ohm}$ resistance and $0.1 \mathrm{H}$ inductance connected in series. In order to reduce the magnitude of $23^{\text {rd }}$ and $25^{\text {th }}$ harmonics the conduction angle of the inverter is set to $\sigma=172.5^{\circ}$. The output voltage expressions derived for the 24-pulse inverter are validated with simulated results and are highlighted in Table II. The combined multipulse-multilevel 
inverter configuration produces almost a near sinusoidal output voltage with a total harmonic distortion of about $3.81 \%$ as depicted in Figs.9 and 10 respectively.

\section{TABLE II COMPARISON OF ANALYTICAL AND SIMULATED RESULTS}

\begin{tabular}{|c|c|c|}
\hline \multirow{2}{*}{$\begin{array}{c}\text { Significant } \\
\text { Harmonics }\end{array}$} & \multicolumn{2}{|c|}{ Peak output voltage (volts) } \\
\cline { 2 - 3 } & Analytical & Simulation \\
\hline $23^{\text {rd }}$ & 25.095 & 25.21 \\
\hline $25^{\text {th }}$ & 23.087 & 24.27 \\
\hline $47^{\text {th }}$ & 187.36 & 189.56 \\
\hline $49^{\text {th }}$ & 179.715 & 183.02 \\
\hline
\end{tabular}

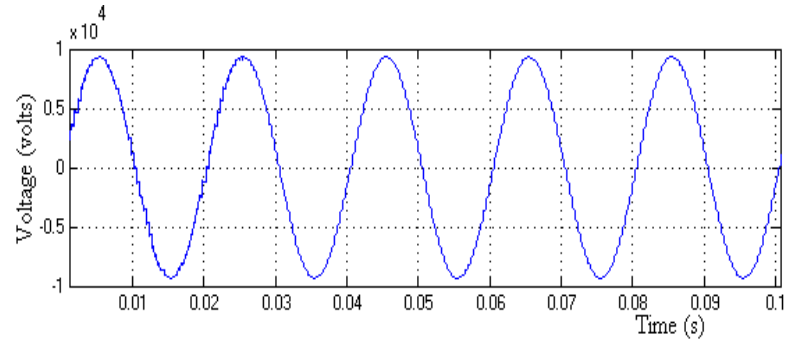

Fig 9 Multipulse-multilevel inverter output voltage

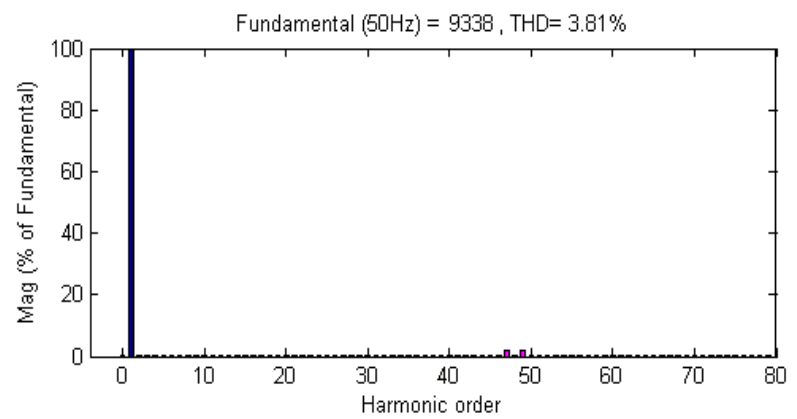

Fig 10 Multipulse-multilevel inverter output voltage THD

\section{CONCLUSION}

A combined multipulse-multilevel inverter topology suitable for high power applications has been proposed. The pulse pattern and the phase shifting transformer arrangement for harmonic neutralization have been discussed in detail. The analytic expressions for the proposed inverter topology are derived using Fourier series and found to closely agree with the simulated results. This new inverter configuration produces almost three phase sinusoidal voltage and maintains THD well below 4\%. Thus the proposed inverter is highly suitable for power system applications.

\section{REFERENCES}

[1] Diego Soto and Tim.C. Green, "A comparison of High-Power Converter Topologies for the implementation of FACTS Controllers", IEEE Transactions on Industrial Electronics, vol.49, 2002, pp.1072-1080.

[2] Bhim Singh, G. Bhuvaneswari and Vipin Garg, "Harmonic mitigation using 12-pulse ac-dc converter in Vector Controlled Induction Motor Drives", IEEE Transactions on Power Delivery, vol.21, no.3,2006, 1483-1492.
[3] Ricardo Davalos M., Juan M. Ramirez and O. Ruben Tapia, "Three-phase multi-pulse converter STATCOM analysis", Electric Power and Energy Systems, vol.27, 2005, pp.39-51.

[4] Bhim Singh and R. Saha, "A New 24-Pulse STATCOM for voltage regulation", Proceedings of International Conference on Power Electronics, Drives and Energy systems, PEDES 2006, 2006, 8B-03.

[5] L. Gyugyi and N. G. Hingorani, "Understanding FACTS: Concepts and Technology of Flexible AC Transmission Systems", IEEE press, New York, 1999.

[6] A. Nabae, Akira Takahashi, Isao Akagi and Hirofumi, "A new neutral point clamped PWM inverter", IEEE Transactions on Industry Applications, vol.IA-7, no.5, 1981, 518-523.

[7] X.Yuan and I.Barbi, "Fundamentals of a new diode clamping multilevel inverter", IEEE Transactions on Power Electronics, vol.15, no.4, 2002, pp.711-718.

[8] J.S.Lai and F.Z.Peng, "Multilevel converters - A new breed of power converters", IEEE Transactions on Industrial Applications, vol.32, 1996, pp.509-517.

[9] F.G.Peng and J.S.Lai, "Multilevel cascade voltage source inverter with separate dc sources", U.S. Patent 5642 275, 1997.

[10] J. Rodriguez, J.S.Lai and F.Z.Peng, "Multilevel inverters: A survey of topologies, controls and applications", IEEE Transactions on Industrial Electronics, vol.49, no.4, 2002, 724-738.

[11] F.Z.Peng, J.S.Lai, J.W.McKeever and J.A.Vancoevering, "Multilevel voltage source inverter with separate dc sources for static var generation", IEEE Transactions on Industrial Applications, vol.32, no.5, 1996, pp.1130-1138.

B.Geethalakshmi received Bachelor of Engineering in 1996 and Master of Engineering in 1999 from Bharathidasan University. She is completed her Ph.D work in power electronics applications in power systems. She published paper in international journals and presented research papers in various international conferences. Her areas of interest include power converters such as ac-dc-ac converters, matrix converter and power factor correction techniques.

P.Dananjayan received Bachelor of Science from University of Madras in 1978, Bachelor of Technology in 1982 and Master of Engineering in 1984 from the Madras Institute of Technology, Chennai and Ph.D degree from Anna University, Chennai in 1998. He is working as a Professor and Head of the Department of Electronics and Communication Engineering, Pondicherry Engineering College, Pondicherry, India. He has more than 60 publications in National and International Journals. He has presented more than 130 papers in National and International conferences. He has produced $6 \mathrm{Ph} . \mathrm{D}$ candidates and is currently guiding eight Ph.D students. His areas of interest include power electronics application in power system, ATM Networks, Wireless Communication and Spread spectrum Techniques. 